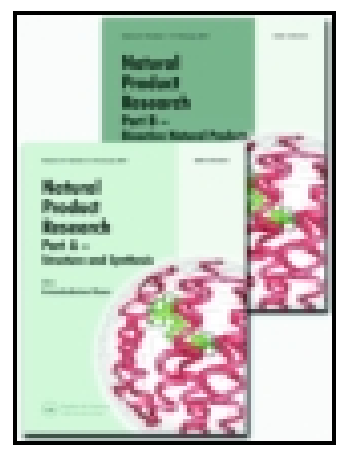

Natural Product Research

Formerly Natural Product Letters

ISSN: 1478-6419 (Print) 1478-6427 (Online) Journal homepage: https://www.tandfonline.com/loi/gnpl20

\title{
Vascular effects of a polyphenolic fraction from Oxalis pes-caprae L.: role of $\alpha$-adrenergic receptors Sub-types
}

\section{Diogo A. Fonseca, Mónica Ferreira, Maria Graça Campos, Pedro E. Antunes, Manuel J. Antunes \& Maria Dulce Cotrim}

To cite this article: Diogo A. Fonseca, Mónica Ferreira, Maria Graça Campos, Pedro E. Antunes, Manuel J. Antunes \& Maria Dulce Cotrim (2019): Vascular effects of a polyphenolic fraction from Oxalis pes-caprae L.: role of $\alpha$-adrenergic receptors Sub-types, Natural Product Research, DOI: 10.1080/14786419.2018.1564291

To link to this article: https://doi.org/10.1080/14786419.2018.1564291

View supplementary material \lceil

Published online: 30 Jan 2019.

Submit your article to this journal $\pi$

View Crossmark data $[\pi$ 


\title{
Vascular effects of a polyphenolic fraction from Oxalis pes-caprae L.: role of $\alpha$-adrenergic receptors Sub-types
}

\author{
Diogo A. Fonseca ${ }^{a, b}$, Mónica Ferreira ${ }^{a}$, Maria Graça Campos ${ }^{\text {d,e }}$, Pedro E. \\ Antunes $^{\mathrm{e}}$, Manuel J. Antunes ${ }^{\mathrm{e}}$ and Maria Dulce Cotrim ${ }^{\mathrm{a}, \mathrm{b}}$ \\ aLaboratory of Pharmacology and Pharmaceutical Care, Faculty of Pharmacy University of Coimbra, \\ Coimbra, Portugal; ${ }^{\mathrm{b} C o i m b r a}$ Institute for Clinical and Biomedical Research (iCBR), Faculty of

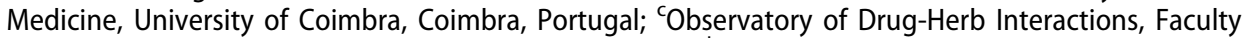 \\ of Pharmacy, University of Coimbra, Coimbra, Portugal; ${ }^{d}$ Center of Chemistry, Faculty of Sciences \\ and Technologies, University of Coimbra, Coimbra, Portugal; ${ }^{\mathrm{e} C e n t e r}$ of Cardiothoracic Surgery, \\ University Hospital and Faculty of Medicine of Coimbra, Coimbra, Portugal
}

\section{ABSTRACT}

Oxalis pes-caprae L. is a plant of the Oxalidaceae family, from which several compounds have been previously identified. Recently, we showed that an Oxalis pes-caprae L. extract inhibits the vasopressor effect of noradrenaline. In this work we aimed to explore the mechanisms involved in this effect. The results confirmed that the flavonoid fraction present in the extract inhibits noradrenaline-induced contractions and that this effect is concentration-dependent. Also, a parallel shift to the right in the noradrenaline concentration-response curve was observed, suggesting a decrease in efficacy and also in potency. Together these results support the assumption that the extract could exert a non-competitive antagonism on the $\alpha$-adrenergic receptors. However, experiments in the presence of competitive antagonists for $\alpha$-adrenergic receptor sub-types (i.e. prazosin, yohimbine and phentolamine) showed that the effect may not be directly mediated by $\alpha$-adrenergic receptors. Thus, the interaction of this extract with the adrenergic system remains to be confirmed.

\section{ARTICLE HISTORY}

Received 17 June 2018

Accepted 14 December 2018

\section{KEYWORDS}

adrenergic; flavonoids; human internal thoracic artery; Oxalis pes-caprae L.

\section{Introduction}

Our group has previously characterized the polyphenolic content of an aqueous leaf extract of Oxalis pes-caprae L. and evaluated its vascular activity and potential 
antioxidant, anti-inflammatory and neuroprotective properties (Gaspar et al. 2018). In that study, we showed that the extract exhibited antioxidant activity and significantly affected the contractile response to noradrenaline. In the present study, we focused on the vascular effects of the leaf extract of Oxalis pes-caprae L.

Oxalis pes-caprae L. is an invasive weed abundant in Mediterranean zones (DellaGreca et al. 2007; Ferrero et al. 2015) from which several compounds have been previously identified by DellaGreca et al. (2007, 2009, 2010, 2008), such as cinnamate derivatives, aromatic compounds and phenols. In our previous study we also identified luteolin and apigenin derivatives in the leaves of this plant (Gaspar et al. 2018).

The leaves of Oxalis pes-caprae L. have been used in the traditional medicine for their antihypertensive effects while its roots to their diuretic activity (Aprilita et al. 2013; Güçlütürk et al. 2012), thus suggesting a potential use of these bioactive compounds in the context of cardiovascular disease. Accordingly, we recently showed that the leaf flavonoid extract of Oxalis pes-caprae L. inhibits the contractile response of the human internal thoracic artery (HITA, also known as internal mammary artery) to noradrenaline (Gaspar et al. 2018). In this work we aimed to determine whether this inhibition is concentration-dependent and to assess the potential involvement of specific sub-types of $\alpha$-adrenergic receptors in these effects.

\section{Results and discussion}

\subsection{Inhibition of contractile response is concentration-dependent}

The leaf extract of Oxalis pes-caprae L. did not induce vasoconstriction (results not shown), which confirmed our previous results (Gaspar et al. 2018). The increasing concentration of extract produced a concentration-dependent inhibitory effect on the contractile response to noradrenaline (Figure S1). As seen in Table S1, the decrease in maximal contraction (significant for the 5.2 and $10.4 \mathrm{mg} / \mathrm{mL}$ concentrations $-85.91 \%$ and $87.76 \%$, respectively) was accompanied by a parallel shift of the noradrenaline cumulative concentration-response curve to the right, thus indicating a decrease in potency which was also significant for the 5.2 and $10.4 \mathrm{mg} / \mathrm{mL}$ concentrations. Together these results suggested that the extract could exert a concentration-dependent non-competitive antagonism on the adrenergic receptors. Such results are in agreement with previous studies that showed inhibitory effects of flavonoids (such as luteolin and homoorientin) on the contractile response in rat isolated thoracic aorta (Woodman et al. 2005).

Furthermore, other studies have shown the vasodilatory potential of flavonoids such as luteolin and apigenin (Abdalla et al. 1994; Duarte et al. 1993). Several mechanisms have been implicated in this vasodilatory effect, namely: (a) decreased calcium uptake in vascular smooth muscle cells (Abdalla et al. 1994; Shoshan et al. 1980), (b) inhibitory effect on cyclic adenosine monophosphate (cAMP) and cyclic guanosine monophosphate (cGMP) phosphodiesterase (Laekeman et al. 1986) or (c) protein kinase $C$ activity (Duarte et al. 1993). In the case of apigenin, the vasodilation effect appears to be partially related to increased levels of cGMP, whereas luteolin may have a CAMP-mediated inhibitory effect on noradrenaline-induced contractions (Scuro et al. 
2004; Shoshan et al. 1980). Moreover, mechanical removal of the endothelium did not modify the flavonoid vasodilatory properties (Shoshan et al. 1980).

Studies with orientin from bamboo leaves (Phyllostachys nigra), in rings of thoracic aortas isolated from New Zealand rabbits, suggest that this flavonoid may produce vasodilation in pre-contracted rings via the nitric oxide-cGMP pathway in the vascular smooth muscle. Furthermore, mechanisms involving potassium channels, $\beta$-adrenergic receptors and CAMP do not appear to be involved in these effects (Fu et al. 2005).

\subsection{Vascular effect may not be directly mediated by $\alpha$-adrenergic receptors}

The second aim of this study was to evaluate the potential involvement of specific sub-types of $\alpha$-adrenergic receptors in the vascular effects of the leaf extract of Oxalis pes-caprae L. To this purpose, we performed cumulative concentration-response curves to noradrenaline in the presence of the higher concentration of extract (i.e. $10.4 \mathrm{mg} /$ $\mathrm{mL}$ ) and several antagonists for $\alpha$-adrenergic receptors, specifically prazosin (competitive antagonist selective for $\alpha_{1}$-adrenergic receptors), yohimbine (competitive antagonist selective for $\alpha_{2}$-adrenergic receptors) and phentolamine (non-selective competitive antagonist). As shown in Figure S2, the contractile response induced by noradrenaline was mediated by both receptor sub-types, with a higher contribution from the $\alpha_{2}$ subtype (a higher significant decrease in maximal contraction was seen with prazosin $87.57 \%$ of control). These results are somehow contradictory to previous studies which showed a higher contribution of the $\alpha_{1}$-adrenergic receptors in the contractile response of the HITA to noradrenaline (Giessler et al. 2002; Pesic et al. 2003). Nevertheless, the $\alpha_{2}$-adrenergic receptors have been previously implicated in the contractile response of other vessel grafts such as the saphenous vein to noradrenaline (Giessler et al. 2002).

Interestingly, the extract of Oxalis pes-caprae $\mathrm{L}$ did not inhibit the contractile response to noradrenaline in the presence of the three receptor antagonists (Figure S2 and Table S2). Therefore, the flavonoid fraction present in the extract of Oxalis pescapre L. used in this study does not seem to have affinity for both $\alpha_{1}$ and $\alpha_{2}$ adrenergic receptors. Since there was no direct effect on $\alpha$-adrenergic receptors, the inhibition of noradrenaline contraction could be mediated by $\beta$-type receptors, thus further experiments should be performed to evaluate the potential involvement of such receptors.

\section{Conclusions}

This study confirmed an inhibitory effect of the flavonoid fraction of the leaf extract of Oxalis pes-caprae L. on the noradrenaline-induced vasoconstriction. Furthermore, our study showed that this inhibitory effect is concentration-dependent and may not be directly mediated by $\alpha$-adrenergic receptors. Further studies are required to establish a structure-activity relationship of the compounds present in this flavonoid extract, to evaluate the potential involvement of $\beta$-adrenergic receptors and to assess the vasodilatory potential of this extract. 


\section{Acknowledgements}

The authors would like to thank the support and help in the collection of samples from the nurses of the Centre of Cardiothoracic Surgery, University Hospital of Coimbra, Portugal.

\section{References}

Abdalla S, Zarga MA, Sabri S. 1994. Effects of the flavone luteolin, isolated from Colchicum richii, on guinea-pig isolated smooth muscle and heart and on blood pressure and blood flow. Phytother Res. 8(5):265-270.

Aprilita R, Maksum R, Abdul M, Suyatna F. 2013. Screening angiotensin converting enzyme (ACE) inhibitor activity of antihypertensive medicinal plants from Indonesia. Int J Pharm Teach Pract. 4:527-532.

DellaGreca M, Previtera L, Purcaro R, Zarrelli A. 2007. Cinnamic ester derivatives from Oxalis pescaprae (Bermuda buttercup). J Nat Prod. 70(10):1664-1667.

DellaGreca M, Previtera L, Purcaro R, Zarrelli A. 2009. Phytotoxic aromatic constituents of Oxalis pes-caprae. Chem Biodivers. 6(4):459-465. Epub 2009/04/09.

DellaGreca M, Previtera L, Zarrelli A. 2010. A new aromatic component from Oxalis pes-caprae. Nat Prod Res. 24(10):958-961.

Dellagreca M, Purcaro R, Previtera L, Zarrelli A. 2008. Phenyl cinnamate derivatives from Oxalis pes-caprae. Chem Biodivers. 5(11):2408-2414.

Duarte J, Perez Vizcaino F, Utrilla P, Jimenez J, Tamargo J, Zarzuelo A. 1993. Vasodilatory effects of flavonoids in rat aortic smooth muscle. Structure-activity relationships. Gen Pharmacol. 24(4):857-862.

Ferrero V, Barrett SC, Castro S, Caldeirinha P, Navarro L, Loureiro J, Rodriguez ES. 2015. Invasion genetics of the Bermuda buttercup (Oxalis pes-caprae): complex intercontinental patterns of genetic diversity, polyploidy and heterostyly characterize both native and introduced populations. Mol Ecol. 24(9):2143-2155.

Fu XC, Wang MW, Li SP, Zhang Y, Wang HL. 2005. Vasodilatation produced by orientin and its mechanism study. Biol Pharm Bull. 28(1):37-41.

Gaspar MC, Fonseca DA, Antunes MJ, Frigerio C, Gomes NGM, Vieira M, Santos AE, Cruz MT, Cotrim MD, Campos MG. 2018. Polyphenolic characterisation and bioactivity of an Oxalis pescaprae L. leaf extract. Nat Prod Res. 32(6):732-738.

Giessler C, Wangemann T, Silber RE, Dhein S, Brodde OE. 2002. Noradrenaline-induced contraction of human saphenous vein and human internal mammary artery: involvement of different alpha-adrenoceptor subtypes. Naunyn Schmiedebergs Arch Pharmacol. 366(2):104-109.

Güçlütürk I, Detsi A, Weiss EK, loannou E, Roussis V, Kefalas P. 2012. Evaluation of anti-oxidant activity and identification of major polyphenolics of the invasive weed Oxalis pes-caprae. Phytochem Anal. 23(6):642-646.

Laekeman G, Glaeys M, Rwangabo P, Herman A, Vlietinck A. 1986. Cardiovascular effects of 3-methylquercetin. Planta Med. 52(6):433-437.

Pesic S, Grbovic L, Jovanovic A, Radenkovic M, Stojic D. 2003. Effect of the vascular endothelium on contractions induced by noradrenaline and phenylephrine in perforating branch of the human internal mammary artery. Pol J Pharmacol. 55:581-593.

Scuro LS, Simioni PU, Grabriel DL, Saviani EE, Modolo LV, Tamashiro WMSC, Salgado I. 2004. Suppression of nitric oxide production in mouse macrophages by soybean flavonoids accumulated in response to nitroprusside and fungal elicitation. BMC Biochem. 5(1):5.

Shoshan V, Campbell KP, MacLennan DH, Frodis W, Britt BA. 1980. Quercetin inhibits Ca2+ uptake but not $\mathrm{Ca} 2+$ release by sarcoplasmic reticulum in skinned muscle fibers. Proc Natl Acad Sci U S A. 77(8):4435-4438.

Woodman OL, Meeker WF, Boujaoude M. 2005. Vasorelaxant and antioxidant activity of flavonols and flavones: structure-activity relationships. J Cardiovasc Pharmacol. 46(3):302-309. 